\title{
Formação cocriada e colaborativa nas unidades de saúde
}

Paula Broeiro*

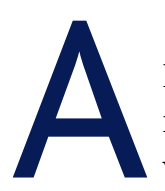
escrita de um editorial é sempre um desafio. Este consistirá na narrativa de uma experiência potencialmente adversa que se converteu num enorme ganho pessoal e profissional. Será, pois, um editorial escrito na primeira pessoa.

Em março de 2016 fui informada, por uma colega, de que integrava um júri do concurso de consultor da carreira médica, cuja composição havia sido refeita. Foi um misto de emoções associadas à apreensão com a responsabilidade da avaliação da progressão de colegas, à sobrecarga acrescida num período em que me encontrava em tempo parcial, usufruindo de um direito legal que me havido sido reconhecido. Pedi escusa, invocando a situação de trabalho a tempo parcial. Quando recebi o telefonema acerca do meu pedido de escusa, já tinha ocorrido a primeira reunião do júri e sido estabelecido um compromisso interpessoal entre os seus membros. Apesar dos constrangimentos pessoais aceitei continuar, pois que, centrando-me nos candidatos, seriam estes os prejudicados com um novo adiamento das provas do concurso.

Como é do conhecimento dos médicos, a avaliação para a progressão na carreira é efetuada mediante o cumprimento de legislação própria, cujos requisitos incluem a entrega de Curriculum Vitae (CV) e uma prova pública, que compreende a discussão do CV e uma prova prática ${ }^{1}$ (análise de um caso clínico). ${ }^{2}$

Cumprindo todos os procedimentos concursais, o primeiro desafio foi a avaliação curricular para a qual o júri utilizou a grelha publicada na página do Colégio de Medicina Geral e Familiar da Ordem dos Médicos, ${ }^{3}$ introduzindo pequenas alterações. A sua aplicação causou grande desconforto pela falta de coerência na distribuição da pontuação quanto ao exercício clínico (e.g.,

*Directora da Revista Portuguesa de Medicina Geral e Familiar ponderação semelhante para a elaboração de um folheto como para a atividade assistencial), quanto à formação recebida (em que é pontuada a quantidade e não a sua relevância) e quanto à pouca valorização da aquisição de competências. A referida grelha merece uma revisão reflexiva e o envolvimento colaborativo de especialistas em avaliação.

O espaço de liberdade do júri foi a prova prática: depois de acordado o modelo de prova, definiram-se os critérios de avaliação e desenhou-se o modelo de construção dos casos. A construção dos casos teve como objetivos harmonizar a tipologia e a extensão de dados a fornecer a cada candidato, garantindo que não se fariam perguntas em cascata, e não expor o júri (e.g., role playing). Assumiu-se que ao candidato se forneceria a história clínica (história pessoal e social, lista de problemas, exames complementares e terapêutica regular) e os itens S(ubjetivo) e O(bjetivo) das notas de seguimento do registo médico orientado por problemas. ${ }^{4}$ Os casos clínicos deveriam, por razões éticas e questões de sigilo/confidencialidade, ser criados (mesmo que inspirados em casos reais) e, atendendo à fase da carreira profissional dos candidatos (pelo menos, cinco anos de exercício), ter complexidade (e.g., exigir definição de prioridades, gestão terapêutica, aplicação de normas de orientação clínica a par de cuidados preventivos, coordenação e/ou articulação de cuidados). ${ }^{5}$ Atendendo à incerteza ${ }^{6}$ inerente à prática de medicina geral e familiar, o que se avaliaria seriam os restantes itens do método deWeed: ${ }^{4} \mathrm{~A}$ (valiação) e $\mathrm{P}($ lano). Os parâmetros orientadores da avaliação ${ }^{7}$ foram definidos para: A [abordagem holística, capacidade de interpretar (julgamento clínico), gestão clínica (e.g., multimorbilidade, a incerteza e risco) e discussão (clarificação dos itens anteriores)] e $\mathbf{P}$ [capacidade de decisão (e.g., prioridades e justificação das escolhas), mobilização de recursos, gestão da complexidade (e.g., respeito pela 
globalidade e individualidade, compreensão das diferentes interações e das consequências da intervenção) e discussão].

Sendo o júri constituído por médicos não especialistas em avaliação e tratando-se de um concurso para a aquisição do grau de consultor, o caso clínico seria o mote para melhor avaliar indiretamente a competência clínica. O desenho da prova teve subjacente a necessidade de avaliar diferentes dimensões de competência: ${ }^{8}$ conhecimentos e sua aplicação, capacidade de interpretar testes de diagnóstico, raciocínio clínico, capacidade de identificar e resolver problemas, comunicação, capacidade de trabalhar em equipa e mobilizar recursos, capacidade de expressar dilemas clínicos.

A cada candidato foi dada a oportunidade de tirar à sorte um de cinco casos, foi fornecido um tempo aproximado de consulta ( 15 minutos) para ler e fazer a avaliação do caso e estabelecer o plano para o doente, de acordo com os dados disponíveis. Os candidatos apresentaram a sua avaliação e plano, justificando-os, tendo o júri pontualmente de fazer perguntas de clarificação. Cada prova revelou ser a expressão da competência profissional de cada candidato e na maioria dos casos o reflexo da maturidade da equipa que integram e do seu percurso profissional.

As provas públicas do concurso tornaram-se uma experiência gratificante pelo trabalho da equipa quase espontânea - júri - e sobretudo pela forma como os candidatos corresponderam e concretizaram a expectativa do júri através do seu exercício de avaliação e planeamento integrado de cuidados. Esta experiência mereceu-me uma reflexão sobre o papel das nossas unidades de saúde enquanto comunidades de prática e de formação médica contínua. Desconhecendo em concreto qual o modelo organizativo de ensino-aprendizagem da unidade de saúde de cada candidato, os casos apresentados seguiram um modelo não-linear. A diversidade de percursos, na discussão com cada candidato, no sentido de saber até onde eram capazes de caminhar como profissionais autónomos, pensantes, críticos e atuantes, permitiu ter argumentos suficientes para atribuir a cada um a classificação, a que a lei obriga, e compreender de que modos diferentes tinham construído as suas competências e as tinham (ou não) aprofundado.

O volume e a complexidade do conhecimento e das tecnologias colocam desafios à competência ${ }^{9}$ dos pro- fissionais de saúde e as adquiridas no final da formação específica são insuficientes para assegurar o desempenho de elevada qualidade ao longo da vida. ${ }^{10} \mathrm{O}$ desenvolvimento profissional contínuo (DPC) é um processo cíclico e gradual em espiral, de regresso aos mesmos temas com maturidade e/ou profundidade diferentes. ${ }^{9}$ As competências são contextuais e refletem a relação entre capacidades individuais e tarefas/necessidades reais do lugar de prática. ${ }^{8,11-12} \mathrm{O}$ que vem reforçar a perceção de que cada candidato expressou o seu desenvolvimento profissional, a circunstância do seu exercício e de que as suas unidades de saúde poderiam ter sido comunidades de prática. As comunidades de prática baseiam-se nas relações entre médicos, em cuidados centrados no paciente eficazes, na flexibilidade adquirida num ambiente de constante reavaliação da aprendizagem através de casos. ${ }^{5}$ Neste modelo, os profissionais definem objetivos comuns (colaborativos), planos de saúde cocriados e envolvem-se numa aprendizagem e práticas reflexivas. ${ }^{5}$ Nestas comunidades, os membros estão dispostos a aprender com a sua prática comum, assumir como seus os objetivos dos outros, partilhar as suas histórias de sucesso e fracasso, e promover a evolução contínua da aprendizagem coletiva ${ }^{5}$, o que requer mecanismos de feedback adequados..$^{5,11-12}$

A atualização de conhecimentos e competências para os médicos não é nova - historicamente, o modelo de aprendizagem educação médica contínua (EMC) tem perpetuado a aprendizagem como um complemento à prática diária. ${ }^{10} \mathrm{~A}$ evolução dos modelos de EMC para DPC tende para atividades de aprendizagem em grupo, realistas, orientadas às competências de prestação de cuidados e às necessidades/preferências dos médicos, mensuráveis pelos ganhos de conhecimento, desempenho clínico e/ou melhoria dos resultados em saúde..$^{10} \mathrm{O}$ isolamento profissional é hoje reconhecido como o principal obstáculo ao DPC. ${ }^{10}$

O ambiente de prática é rico em oportunidades de identificação de necessidades educacionais e geração de soluções, bem como propicia o desenvolvimento de conhecimento e competência (e.g., cognitiva, funcional, social, ética) alinhados com as fases de progressão profissional. ${ }^{9}$ A avaliação desempenha um papel integrante do processo, uma vez que confirma em que medida foram adquiridas competências ao longo da vida. ${ }^{9}$

Os conceitos de cocriação, colaboração e criativida- 
de, apesar de aplicados à investigação, ${ }^{13}$ têm paralelo na aprendizagem médica. Em Portugal existem seguramente experiências formativas de sucesso que deveriam ser publicadas.

O concurso de consultor como experiência positiva levou-me a questionar se será necessário implementar um novo modelo de creditação ou se não seria adequado e oportuno aperfeiçoar o existente.

\section{REFERÊNCIAS BIBLIOGRÁFICAS}

1. Decreto-Lei no 177/2009, de 4 de agosto. Diário da República. $1^{\text {a }}$ Série(149).

2. Portaria n.o 217/2011, de 31 de maio. Diário da República. $1^{\text {a }}$ Série(105).

3. Colégio da Especialidade de Medicina Geral e Familiar. Grelha de avaliação da prova curricular do procedimento concursal de habilitação ao grau de consultor da carreira médica: especialidade de medicina geral e familiar. Lisboa: Ordem dos Médicos; 2015. p. 354-68.

4. Weed LL. Medical records that guide and teach. N Engl J Med. 1968;278(11):593-600.

5. Soubhi $H$, Bayliss EA, Fortin $M$, Hudon $C$, van den Akker $M$, Thivierge $R$, et al. Learning and caring in communities of practice: using relationships and collective learning to improve primary care for patients with multimorbidity. Ann Fam Med. 2010;8(2):170-7.
6. Yaphe J. Teaching and learning about uncertainty in family medicine. Rev Port Med Geral Fam. 2014;30(5):286-7.

7. Gerada C, Riley B, Simon C. Preparing the future GP: the case for enhanced GP training [Internet]. London: Royal College of General Practitioners; 2012. Available from: http://www.rcgp.org.uk/policy/rcgp-policyareas/ /media/Files/Policy/A-Z-policy/Case_for_enhanced_GP_ training.ashx

8. Epstein RM. Assessment in medical education. N Engl J Med. 2007;356(4):387-96.

9. Broeiro P. Conhecimento e competência. Rev Port Med Geral Fam. 2015;31(2):82-4.

10. Horsley T, Grimshaw J, Campbell C. How to create conditions for adapting physicians' skills to new needs and lifelong learning [Internet]. Copenhagen: World Health Organization; 2010. Available from: http://www.euro. who.int/_data/assets/pdf_file/0020/124418/e94294.pdf

11. Milner RJ, Gusic ME, Thorndyke LE. Perspective: toward a competency framework for faculty. Acad Med. 2011;86(10):1204-10.

12. Miller A, Archer J. Impact of workplace based assessment on doctors' education and performance: a systematic review. BMJ. 2010;341:c5064.

13. Greenhalgh T, Jackson C, Shaw S, Janamian T. Achieving research impact through co-creation in community-based health services: literature review and case study. Milbank Q. 2016;94(2):392-429.

\section{ENDEREÇO PARA CORRESPONDÊNCIA}

director@rpmgf.pt 